\title{
Transactions
}

\section{Mapping the formation areas of giant molybdenum blue clusters: a spectroscopic study $\dagger$}

\author{
Bogdan Botar, ${ }^{* a}$ Arkady Ellern ${ }^{b}$ and Paul Kögerler* ${ }^{a, c}$
}

Received 22nd March 2012, Accepted 17th May 2012 DOI: $10.1039 / \mathrm{c} 2 \mathrm{dt} 30661 \mathrm{a}$

The self-assembly of soluble molybdenum blue species from simple molybdate solutions has primarily been associated with giant mixed-valent wheel-shaped cluster anions, derived from the $\left\{\mathrm{Mo}^{\mathrm{V} / \mathrm{VI}}{ }_{154 / 176}\right\}$ archetypes, and a $\left\{\mathrm{Mo}^{\mathrm{V} / \mathrm{VI}} 368\right\}$ lemon-shaped cluster. The combined use of Raman spectroscopy and kinetic precipitation as self-assembly monitoring techniques and single-crystal X-ray diffraction is key to mapping the realm of molybdenum blue species by establishing spherical $\left\{\mathrm{Mo}^{\mathrm{V} / \mathrm{VI}}{ }_{102}\right\}$-type Keplerates as an important giant molybdenum blue-type species. We additionally rationalize the empirical effect of reducing agent concentration on the formation of all three relevant skeletal types: wheel, lemon and spheres. Whereas both wheels and the lemon-shaped $\left\{\mathrm{Mo}^{\mathrm{V} / \mathrm{VI}}{ }_{368}\right\}$ cluster are obtained from weakly reduced molybdenum blue solutions, considerably higher reduced solutions lead to $\left\{\mathrm{Mo}^{\mathrm{V} / \mathrm{VI}}{ }_{102}\right\}$-type Keplerates.

\section{Introduction}

Molecular self-assembly represents an attractive strategy for realizing complex hierarchical nanostructures with increasing nuclearity. ${ }^{1-3}$ Possibly one of the most dramatic cases of direct self-assembly in inorganic chemistry involves molybdenum blue solutions, characterized by a deep blue color that readily develops upon reduction of acidified aqueous molybdate solutions. ${ }^{4}$ The identity of the highly soluble species present in these molybdenum blue solutions remained a "mystery" for more than 200 years, aggravated by difficulties in isolating single crystals suitable for X-ray structure determination. Achim Müller and coworkers identified the conditions necessary to grow crystalline samples of two mixed-valent wheel-shaped polyoxomolybdate (v/vI) clusters comprising 154 and 176 Mo centers, respectively, which could formally be decomposed into identical building blocks - a set of either 14 or $16\left\{\mathrm{Mo}_{1}\right\},\left\{\mathrm{Mo}_{2}\right\}$, and $\left\{\mathrm{Mo}_{8}\right\}$ groups assembled into $D_{7 \mathrm{~d}}$ or $D_{8 \mathrm{~d}}$-symmetric structures. ${ }^{5-7}$ Solutions of these multi-nanometer wheels as well as their defect derivatives which lack several $\left\{\mathrm{Mo}_{2}\right\}$-type building blocks were shown $^{5,8}$ to display intense and highly characteristic absorption band patterns in their Raman spectra for NIR excitation lines, caused by a resonance Raman effect due to coincidence of the excitation wavelength $(1064 \mathrm{~nm})$ with those of $\mathrm{Mo}(\mathrm{vI}) \leftarrow \mathrm{Mo}(\mathrm{v})$

${ }^{a}$ Peter Grünberg Institut (PGI-6), Forschungszentrum Jülich GmbH, D-52425 Jülich, Germany.E-mail: b.botar@fz-juelich.de, p.koegerler@fz-juelich.de

${ }^{b}$ Ames Laboratory, Iowa State University, Ames, IA 50011, USA cInstitut für Anorganische Chemie, RWTH Aachen University, D-52074 Aachen, Germany.E-mail: paul.koegerler@ac.rwth-aachen.de

$\dagger$ Electronic supplementary information (ESI) available. CCDC 872867. For ESI and crystallographic data in CIF or other electronic format see DOI: $10.1039 / \mathrm{c} 2 \mathrm{dt} 30661 \mathrm{a}$ intervalence charge transfer (IVCT) absorption transitions. Importantly, the mixed-valent areas of the wheel clusters are localized around the wheel's equator and organized into $\mathrm{Mo}_{5} \mathrm{O}_{6}$ double-cubane compartments over each of which two $\mathrm{Mo}(4 \mathrm{~d})$ electrons are delocalized. This 'compartmentalized' structure implies that the Vis/NIR electronic absorption profile and the resonance Raman signals are independent of ring size $\left(\left\{\mathrm{Mo}_{154}\right\}\right.$ vs. $\left.\left\{\mathrm{Mo}_{176}\right\}\right){ }^{9}$ As the $\left\{\mathrm{Mo}_{2}{ }_{2}\right\}$ building blocks are part of the (fully oxidized) inner rims of the cluster wheels, and not of the mixed-valent $\mathrm{Mo}_{5} \mathrm{O}_{6}$ compartments, their absence in defect derivatives such as $\left\{\mathrm{Mo}_{152}\right\}$ does not significantly affect the Vis/NIR or resonance Raman spectra. The observed electronic absorption transitions are thus independent of wheel type and size. They extend into the visible spectral region and account for the deep blue color of these species. ${ }^{4}$ Subsequently, Müller and co-workers reported an even larger lemon-shaped cluster (dubbed the "blue lemon") with a record $368 \mathrm{Mo}(\mathrm{v} / \mathrm{vI})$ centers, also isolated from reaction solutions very similar to those typically resulting in "molybdenum blue" wheel clusters. ${ }^{10,11}$ This $5.5 \mathrm{~nm}$ cluster, formulated as $\left[\mathrm{H}_{x} \mathrm{Mo}_{368} \mathrm{O}_{1032}\left(\mathrm{H}_{2} \mathrm{O}\right)_{240}-\left(\mathrm{SO}_{4}\right)_{48}\right]^{(x-48)}$ $(x=16)\left(\mathbf{1}\right.$; isolated as $\left.\mathrm{Na}_{48-x} \mathbf{1} \cdot c a \cdot 1000 \mathrm{H}_{2} \mathrm{O}=\mathbf{1 a}\right)$, incorporates three different types of building blocks: $64\left\{\mathrm{Mo}_{1}\right\}, 32$ $\left\{\mathrm{Mo}_{2}\right\}$, and 40 pentagonal $\left\{(\mathrm{Mo}) \mathrm{Mo}_{5}\right\}$ groups (Fig. 1). The formation of the $\left\{\mathrm{Mo}_{368}\right\}$ cluster $\mathbf{1}$ instead of wheel-type species was simply attributed to the use of excess sulfate ions and the presence of $\mathrm{Na}^{+}$cations. ${ }^{11}$ It is interesting, however, that all molybdenum blue cluster types (wheels and lemon) are isolated from mixtures containing similar stoichiometric amounts of reducing agents (necessary for the reduction of $\mathrm{Mo}(\mathrm{vI})$ to $\mathrm{Mo}(\mathrm{v})$ ) although the $\left\{\mathrm{Mo}_{368}\right\}$ cluster with its $112 \mathrm{Mo}(4 \mathrm{~d})$ electrons (i.e. an $\mathrm{Mo}^{\mathrm{V}} /\left(\mathrm{Mo}^{\mathrm{V}}+\mathrm{Mo}^{\mathrm{VI}}\right)$ ratio of $\left.30.4 \%\right)$ is considerably higher reduced than any wheel species. In contrast, all $\left\{\mathrm{Mo}_{154}\right\}$-type species contain $28 \mathrm{Mo}(4 \mathrm{~d})$ electrons; all $\left\{\mathrm{Mo}_{176}\right\}$-type species 

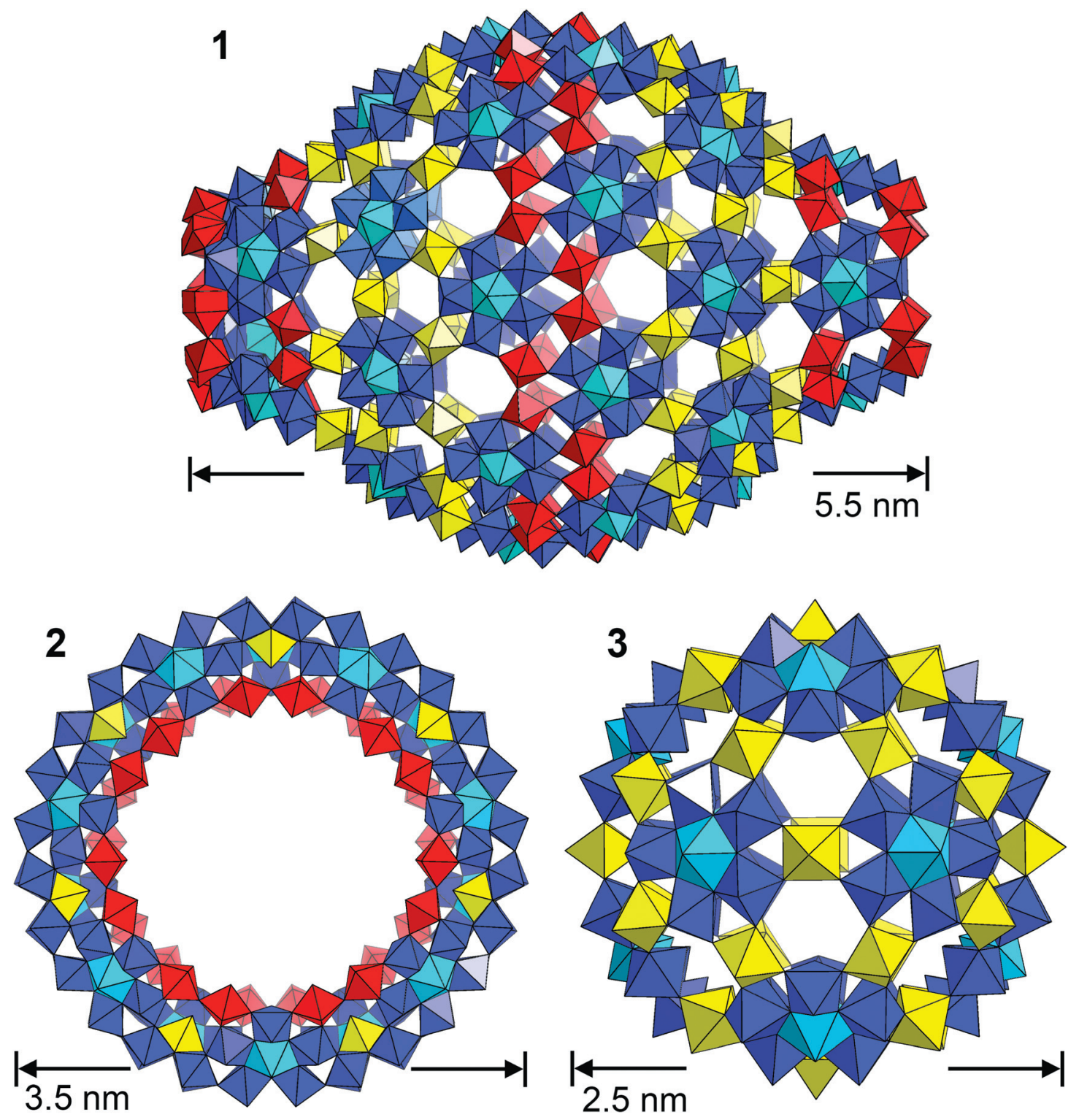

Fig. 1 Polyhedral representations of the metal oxide structures of 1, 2, and $\mathbf{3}$ using standard color codes: ${ }^{32}\left\{(\mathrm{Mo}) \mathrm{Mo}_{5}\right\}$-based building blocks: blue (central $\mathrm{MoO}_{7}$ pentagonal bipyramid: light blue), $\left\{\mathrm{Mo}_{2}\right\}$-type building blocks: red, $\left\{\mathrm{Mo}_{1}\right\}$-type: yellow.

contain $32 \mathrm{Mo}(4 \mathrm{~d})$ electrons (18.2\%). In both types of species the $\mathrm{Mo}(4 \mathrm{~d})$ electrons are delocalized to varying degrees in these nanoscale clusters. The reduction degree $r$ of molybdenum blue solutions from which all these species are obtained is about $15-20 \%$ and is defined here as the percentage of molybdate theoretically reduced to $\mathrm{Mo}(\mathrm{v})$, i.e. $r=\left[\mathrm{Mo}^{\mathrm{V}}\right] /\left(\left[\mathrm{Mo}^{\mathrm{V}}\right]+\left[\mathrm{Mo}^{\mathrm{VI}}\right]\right)$.

Although the discovery of the multi-nanometer sized structures that collectively constitute soluble molybdenum blue has spurred a large number of studies that have expanded our understanding of the formation of these species and helped explain many of their unusual properties, ${ }^{12-15}$ fundamental questions still linger. For instance, to date there is still no viable and general guiding principle that correlates the formation of giant molybdenum blue species as well as their nuclearity with key synthetic parameters such as $\mathrm{pH}$ and reducing agent concentration. Herein we demonstrate how the reducing agent concentration is instrumental in explaining the formation of molybdenum blue clusters and how the rationalization of this effect enables us to expand the known realm of these species. For this purpose we have chosen (resonance) Raman spectroscopy as a valuable in situ tool that facilitates insight into the self-assembly of molybdenum blue and helps us define synthetic boundary conditions under which distinct giant molybdenum blue species can be rationally synthesized and interconverted.

\section{Results and discussion}

\section{Direct self-assembly of Keplerates as prominent molybdenum blue species}

We started by monitoring the self-assembly process of several known wheel-type species from molybdenum blue solutions. One such example was the $\left\{\mathrm{Mo}_{154}\right\}$ compound prepared according to ref. 16. This wheel compound formulated as 


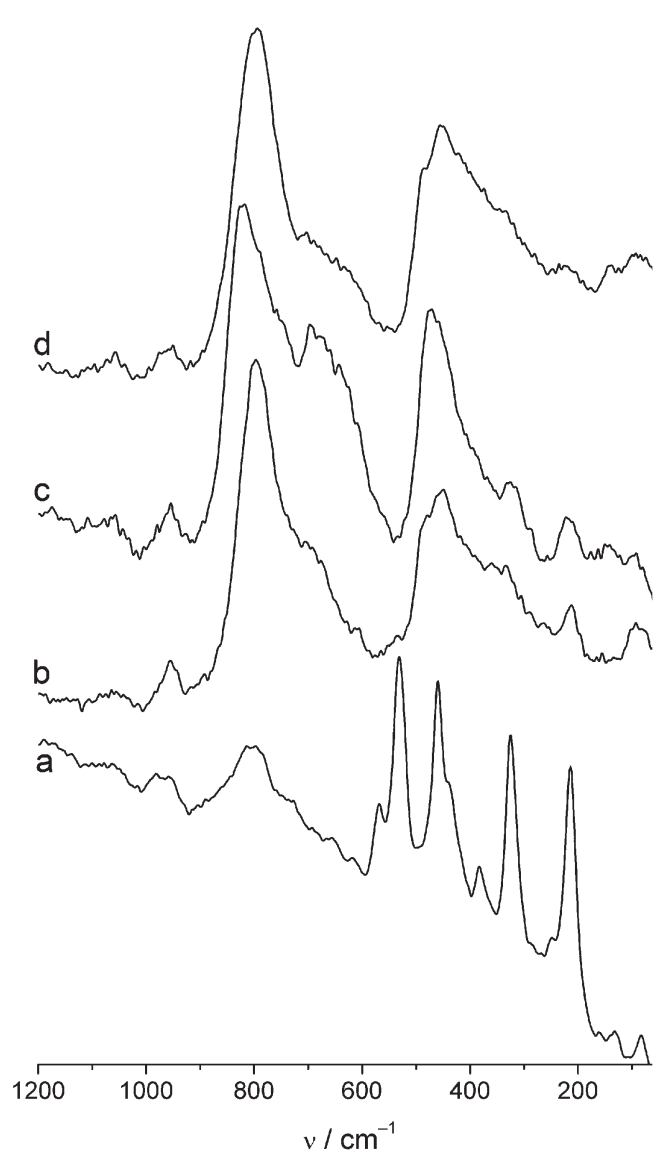

Fig. 2 Resonance Raman spectra of molybdenum blue solutions emphasizing the differences between giant wheel- and Keplerate-containing solutions: (a) mother liquor of the $\left\{\mathrm{Mo}_{154}\right\}$ wheel 2. The spectrum is virtually identical for all giant wheel-based molybdenum blue solutions; (b) the same solution as in (a) but having a five-fold increase of added reducing agent (in this case sodium dithionite); (c) mother liquor of the $\left\{\mathrm{Mo}_{102}\right\}$-type Keplerate 3, five minutes after addition of reducing agent; (d) same solution as in (c) $2 \mathrm{~h}$ after addition of reducing agent.

$\mathrm{Na}_{15}\left\{\left[\mathrm{Mo}^{\mathrm{VI}}{ }_{126} \mathrm{Mo}^{\mathrm{V}}{ }_{28} \mathrm{O}_{462} \mathrm{H}_{14}\left(\mathrm{H}_{2} \mathrm{O}\right)_{70}\right]_{0.5} \quad\left[\mathrm{Mo}^{\mathrm{VI}}{ }_{124} \mathrm{Mo}_{28} \mathrm{O}_{457^{-}}\right.\right.$ $\left.\left.\mathrm{H}_{14}\left(\mathrm{H}_{2} \mathrm{O}\right)_{68}\right]_{0.5}\right\} \cdot c a$. $400 \mathrm{H}_{2} \mathrm{O}(\mathbf{2 a})^{17}$ is prepared by addition of sodium dithionite (calculated to achieve a theoretical reduction degree $r=20 \%$ ) to an acidified molybdate solution at $\mathrm{pH}$ 1. Immediately upon addition of the reducing agent the Raman spectrum of the blue reaction solution showed the highly characteristic line-pattern of wheel-type species in the $200-900 \mathrm{~cm}^{-1}$ range, fully in line with the reported data (Fig. 2a). ${ }^{4,18}$ These characteristic bands include four prominent sharp peaks between 200 and $550 \mathrm{~cm}^{-1}$ (at 214, 325, 460, and $533 \mathrm{~cm}^{-1}$ ) as well as a broad peak at $c a .800 \mathrm{~cm}^{-1}$.

When we increased the amount of reducing agent by a factor of 5 (so that theoretically all the molybdate present can be in principle reduced to Mo(v)) the Raman spectrum of the resulting molybdenum blue solution ( $\mathrm{pH}$ 1) immediately displayed a very different band pattern with a very broad band at around $450 \mathrm{~cm}^{-1}$ instead of the four sharp and intense bands in the $200-550 \mathrm{~cm}^{-1}$ region characteristic of wheel-type species (Fig. 2b). Similar dramatic changes in spectral patterns were obtained from solutions having similar reduction degrees when we replaced sodium dithionite with other reducing agents such as hydrazine sulfate or ascorbic acid. Attempts to isolate crystalline materials suitable for X-ray crystallographic analysis from these solutions proved to be in all cases unsuccessful. However, following the same basic synthetic approach of using excess of reducing agent $(100 \%$ degree of reduction) we succeeded in obtaining crystals suitable for single-crystal X-ray diffraction analysis from acidified aqueous mixtures of reduced molybdate and vanadate. In a typical synthetic procedure a mixture of sodium molybdate and sodium metavanadate was acidified to $\mathrm{pH} 1.0$ and then treated with hydrazine sulfate, the amount of which was calculated such that the entire molybdate and vanadate could be formally reduced to Mo(v) and V(IV) respectively. The Raman spectrum of the resulting mixture again showed a spectral pattern dominated by the two broad bands at 450 and $800 \mathrm{~cm}^{-1}$ respectively, similar to that of analogous molybdenum blue solutions prepared without vanadate (Fig. 2c). After $2 \mathrm{~h}$, the Raman spectrum slightly changes (Fig. 2d), and kinetic precipitation of these solutions with $\mathrm{KCl}$ afforded crystalline samples within minutes. An X-ray crystallographic investigation reveals this molybdenum blue species to contain a spherical Kepleratetype polyoxomolybdate cluster $\mathbf{3}$, isolated as $\mathrm{K}_{8} \mathrm{Na}_{2}(\mathrm{VO})$ $\left[\left\{\mathrm{Mo}_{6} \mathrm{O}_{21}\left(\mathrm{H}_{2} \mathrm{O}\right)_{3}\left(\mathrm{SO}_{4}\right)\right\}_{12}\left(\mathrm{MoO}\left(\mathrm{H}_{2} \mathrm{O}\right)\right)_{30}\right] \cdot 2 \mathrm{~K}_{2} \mathrm{SO}_{4} \cdot c a . \quad 150 \mathrm{H}_{2} \mathrm{O}$ (3a). Note that the use of vanadate, subsequently reduced to vanadyl, in the synthesis of 3a solely facilitates the growth of single crystals, as $\mathrm{VO}^{2+}$ does not get incorporated into the polyanionic framework. ${ }^{19}$ The virtually $I_{\mathrm{h}}$-symmetric polyanion $\mathbf{3}$ shows the usual $\left\{\right.$ pentagon $_{12}$ linker $_{30}$ \} composition of Keplerate cluster structures in which the thirty linker sites are occupied by $\left[\mathrm{Mo}^{\mathrm{V}} \mathrm{O}\left(\mathrm{H}_{2} \mathrm{O}\right)\right]^{3+}$ groups (Fig. 1 and $\mathrm{S} 1 \dagger$ ). The spherical polyanion 3 encapsulates twelve disordered sulfate ligands attached from the inside to each of the 12 pentagonal units in a tridentate mode. Each $\mathrm{S}$ atom is five-fold disordered (five possible orientation attachments of the sulfate groups to the pentagonal units), a feature common to several Keplerates. ${ }^{20-22}$ Nine $\mathrm{K}^{+}$cations were found capping nine of the 20 crown ether-like $\mathrm{Mo}_{6} \mathrm{O}_{6}$ pores in 3. The presence of $\mathrm{Mo}(\mathrm{v})$ centers in the linker positions is supported by bond valence sum (BVS) calculations which give an average value of 5.4 for the 15 crystallographic independent linker sites in 3a. Potentiometric titrations together with elemental analysis results indicate that in addition to the $30 \mathrm{Mo}(\mathrm{v})$ centers, six additional $6 \mathrm{Mo}(4 \mathrm{~d})$ electrons are delocalized over the 12 pentagonal building units. As expected the Vis/NIR electronic spectrum of 3a dissolved in water is dominated by a very intense and broad absorption band with a maximum at $c a$. $760 \mathrm{~nm}$ attributed to $\mathrm{Mo}^{\mathrm{VI}} \leftarrow \mathrm{Mo}^{\mathrm{V}}$ homonuclear IVCT transitions (Fig. 3). Although the same types of electronic transitions dominate the absorption spectrum of wheel type species $\left(\lambda_{\max } c a .750 \mathrm{~nm}\right)$ such as $\mathbf{2}$, in $\mathbf{3}$ these bands are considerably broader in the NIR, allowing for a quick identification of these species in solution (Fig. 3). In this context it is interesting to note that both solutions of $\mathbf{3 a}$ in water, as well as reaction mixtures from which $\mathbf{3 a}$ is isolated, have a considerably darker blue color (with slight violet overtones) compared with analogous solutions of wheel-type species. Interestingly, A. Müller and co-workers reported a related $\left\{\mathrm{Mo}_{102}\right\}$ derivative that, however, was not obtained by direct self-assembly but by oxidative degradation via acidification of a solution containing the larger Keplerate $\left\{\mathrm{Mo}_{132}\right\}$, a molybdenum brown species 


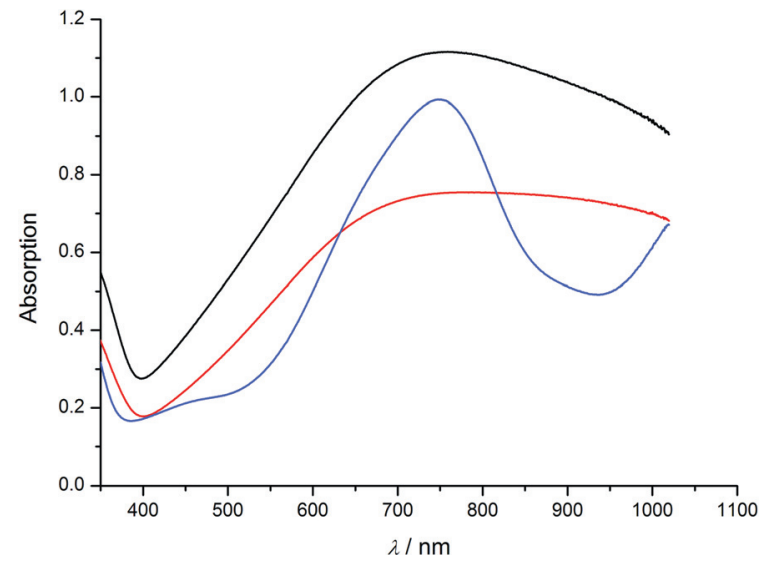

Fig. 3 Electronic absorption spectra in water of the three major molybdenum blue structural types. Black: $0.08 \mathrm{mM}$ solution of 3a; red: $0.029 \mathrm{mM}$ solution of the $\mathrm{Na}^{+}$salt of 1 ; blue: $0.056 \mathrm{mM}$ solution of the $\mathrm{Na}^{+}$salt of the $\left\{\mathrm{Mo}_{154}\right\}$ wheel-type cluster, $2 \mathbf{a}$.

containing carboxylate-bridged $\left\{\mathrm{Mo}_{2}{ }_{2}\right\}$ linker groups with localized Mo-Mo single bonds. ${ }^{23}$ In contrast to polyanion 3, this $\left\{\mathrm{Mo}_{102}\right\}$ degradation product is formulated as the 36-fold reduced neutral cluster $\left[\left\{\mathrm{Mo}^{\mathrm{V} / \mathrm{VI}}{ }_{6} \mathrm{O}_{21}\left(\mathrm{H}_{2} \mathrm{O}\right)_{4} \mathrm{CH}_{3} \mathrm{COO}\right\}_{12}\left(\mathrm{Mo}^{\mathrm{V}}\right.\right.$ $\left.\left.\mathrm{O}\left(\mathrm{H}_{2} \mathrm{O}\right)\right)_{30}\right]$ and incorporates 12 disordered acetate ligands. The isolation of $\mathbf{3 a}$ is significant in that it demonstrates that pure molybdenum oxide-based nanospheres (Keplerates) can be selectively self-assembled by controlling the degree of reduction in molybdenum blue solutions.

\section{Role of reducing agent concentration in the formation and identity of molybdenum blue species}

After establishing the $\left\{\mathrm{Mo}_{102}\right\}$-type Keplerate $\mathbf{3}$ as a distinct component of giant molybdenum blue we focused on the boundary conditions between giant wheels and spheres, in an attempt to rationalize the important effect of reducing agent concentration on the formation of these species. Clearly, chemical reduction is critical in the formation of giant molybdate clusters. Yet, to this date this effect has only been loosely rationalized: it is generally accepted that a higher concentration of reducing agent favors the formation of giant molybdenum brown species such as the $\left\{\mathrm{Mo}_{132}\right\}$ Keplerate (with a reduction ratio of $45.5 \%$ ) over molybdenum blue species. ${ }^{4}$ In contrast to molybdenum blue species which contain a large number of electrons delocalized to varying degrees over large sections of the nanoscopic cluster structure, the brown $\left\{\mathrm{Mo}_{132}\right\}$ Keplerate contains localized and spin-paired $\operatorname{Mo}(\mathrm{v})$ centers in the form of $\operatorname{Mo}(\mathrm{v})-\mathrm{Mo}(\mathrm{v})$ dumbbell groups (Mo-Mo bond distance of $2.6 \AA$ ). ${ }^{24,25}$ However, the $\left\{\mathrm{Mo}_{132}\right\}$ Keplerates self-assemble from molybdates in weakly acidic buffer solutions ( $\mathrm{pH} 4-5),{ }^{24,25}$ conditions under which molybdenum blue species do not form irrespective of the reducing agent concentration. All molybdenum blue species known to date are isolated from considerably stronger acidic aqueous solutions with a $\mathrm{pH} \leq 3$.

As previously noted, we have confirmed the literature method that shows that solutions of acidified aqueous molybdate $(\mathrm{pH} 1)$ reduced to a $20 \%$ degree with sodium dithionite produces giant wheel species. In the preceding section we have shown that an

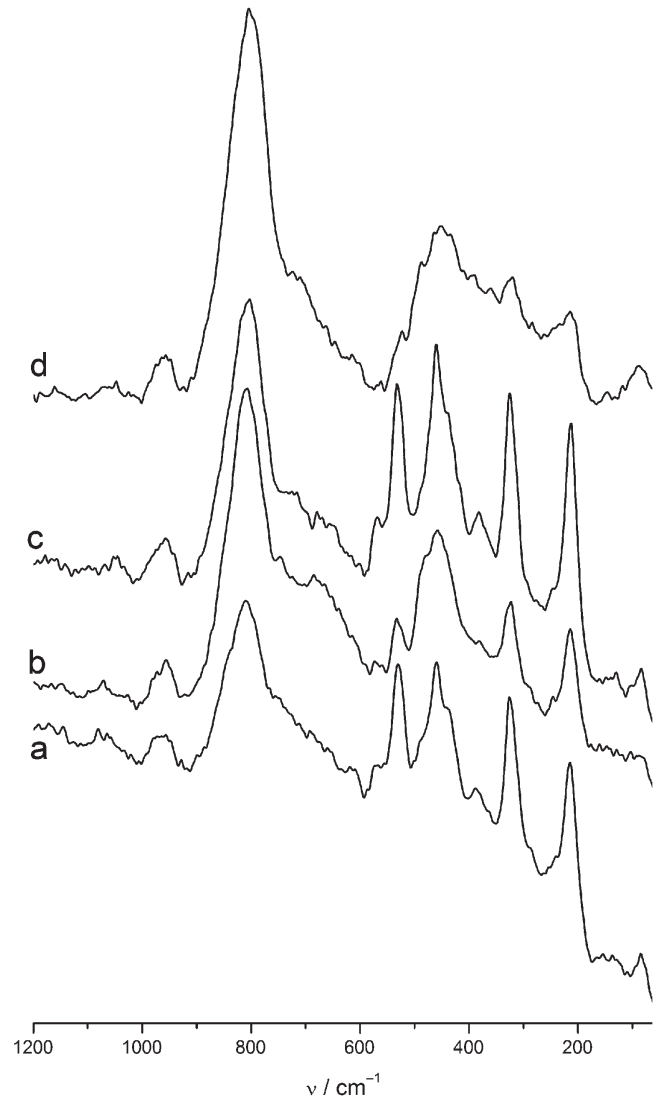

Fig. 4 The effect of added dithionite on the resonance Raman spectra of the reaction solution from which the $\left\{\mathrm{Mo}_{154}\right\}$-type compound $\mathbf{2 a}$ is isolated for a $20 \%$ reduction degree. (a) The solution adjusted to a $40 \%$ reduction degree; (b) a $60 \%$ reduction degree solution $5 \mathrm{~min}$ after addition of dithionite; (c) same solution as in (b) after $1 \mathrm{~h}$; (d) an $80 \%$ reduction degree.

increase in reducing agent concentration to accommodate theoretically a complete reduction to $\mathrm{Mo}(\mathrm{v})(100 \%$ degree of reduction) produces solutions that display a very distinct line pattern in the (resonance) Raman spectrum from which blue Keplerates of the $\left\{\mathrm{Mo}_{102}\right\}$ type such as $\mathbf{3}$ can be isolated. Within these two limits we recorded Raman spectra of the aforementioned mixtures for varying amounts of reducing agent while keeping the other key reaction parameters (concentration and $\mathrm{pH}$ ) constant.

An increase of added sodium dithionite to a degree of reduction of $40 \%$ produces no noticeable changes in the Raman spectra of these solutions showing that giant wheels are still the dominant species under these conditions (Fig. 4a). Moreover, all these solutions produced crystalline salts of the $\left\{\mathrm{Mo}_{154}\right\}$-based derivative 2 within several days (as confirmed by both the crystallographic unit cell parameters and IR spectroscopy). A further increase of added dithionite up to a $60 \%$ reduction degree shows at early reaction stages (five minutes after addition of reducing agent) the emergence of a broad band at $c a .450 \mathrm{~cm}^{-1}$, a feature dominant in solutions containing the Keplerate $\mathbf{3}$ but also some prominent spectral features associated with wheels (Fig. 4b). However, after $1 \mathrm{~h}$, only features associated with wheels were still present (Fig. 4c). The Raman spectrum of the solution having a reduction degree of $80 \%$ displays the two dominant 


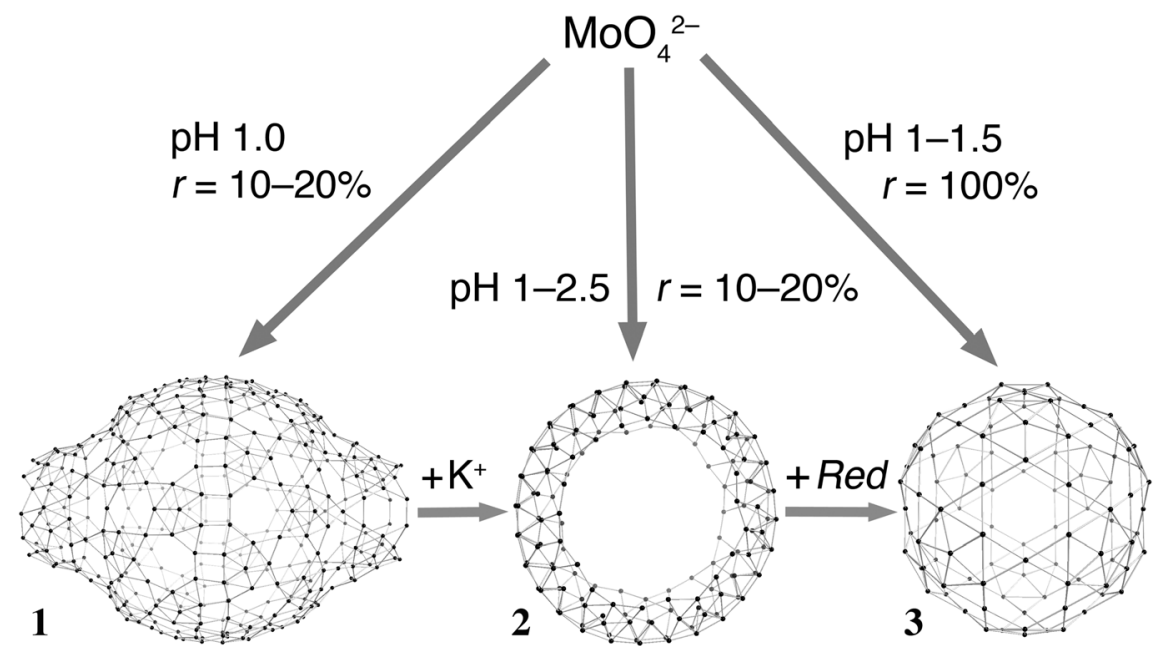

Fig. 5 Schematic illustration of the self-assembled formation of the three distinct molybdenum blue structural types: lemon, wheel and sphere. The key synthetic parameters (reduction degree $r$ and solution $\mathrm{pH}$ ) indicating the ideal conditions for the synthesis and interconversion between the three structural types are emphasized. Note that the synthesis of $\mathbf{1}$ requires the presence of sulfate ions.

broad bands also observed in solutions having a $100 \%$ reduction degree as well as some weak features associated with wheels that diminish over time (Fig. 4d). All these findings appear to contradict an earlier conclusion which states: "This spectrum is rather insensitive to the reaction conditions", ${ }^{4}$ referring to conditions from which molybdenum blue derivatives including the $\left\{\mathrm{Mo}_{154}\right\}$ wheel prepared by the route reinvestigated here, noting that the only difference observed upon increasing the reducing agent concentration was the increase in intensity of the band at $800 \mathrm{~cm}^{-1} .4$ A possible explanation for this disparity and the fact that this dramatic transformation in the Raman spectra of molybdenum blue has remained unaccounted for until now could be the rather high reducing agent concentration necessary to produce these changes. As we will show in the next sections, the reducing agent concentration that defines the formation boundary between wheels and spheres depends considerably on the type of reducing agent and solution $\mathrm{pH}$. However, a clear general pattern becomes evident: transition from wheel-type species to $\left\{\mathrm{Mo}_{102}\right\}$-type Keplerates in molybdenum blue solutions always occurs upon increasing the concentration of added reducing agent. The key reaction parameters that lead to the rapid and selective formation of the two molybdenum-blue cluster-types $\mathbf{2}$ and $\mathbf{3}$ are schematically illustrated in Fig. 5. Rationalizing these results, we propose that the preferred formation of mixed-valent Keplerates with higher $\mathrm{Mo}^{\mathrm{V}}: \mathrm{Mo}^{\mathrm{VI}}$ ratios $v s$. other molybdenum blue species is due to the electrostatic repulsion between the largely delocalized Mo(4d) electrons which is minimized on the surface of a sphere.

\section{Role of $\mathrm{pH}$ in the formation of giant molybdenum blue species}

Traditionally, molybdenum blue species are isolated from acidic aqueous media $(\mathrm{pH} \quad 0.8-3$, and most typically between $\mathrm{pH}$ $1-2.5)$. The effect of $\mathrm{pH}$ on the formation of molybdenum species has been discussed only in connection with giant wheels. The group of A. Müller has shown that while the archetypal $\left\{\mathrm{Mo}_{154}\right\}$ wheel species can be easily obtained from strongly acidic aqueous solutions ( $\mathrm{pH} 1)$, defect versions of this cluster (obtained via removal of loosely bound corner-sharing $\left\{\mathrm{Mo}_{2}\right\}$ groups) can be isolated from considerably less acidic solutions $(\mathrm{pH} 2-3){ }^{26}$ This trend has been generally confirmed by a study of T. Ozeki, although several exceptions were also noted. ${ }^{27}$ In $2001 \mathrm{~A}$. Müller reported a defect ring derivative $\left\{\mathrm{Mo}_{142}\right\}$ prepared by reduction of an acidified molybdate solution with hydrazine sulfate to a $15 \%$ degree of reduction at a $\mathrm{pH}$ of $2.4{ }^{26}$ As expected, the Raman spectrum of this mixture shows the characteristic band pattern associated with wheels. Surprisingly, an increase in reduction degree to $100 \%$ produced no significant changes in the Raman line pattern even after aging the mixture for several days. Only solutions aged for longer periods (three weeks or longer) ${ }^{28}$ display a broadening of the peak at $450 \mathrm{~cm}^{-1}$ observed in solutions from which Keplerate $\mathbf{3}$ is obtained, although even at this stage the spectral features attributed to wheel-type clusters are dominant. This is in stark contrast to more acidic mixtures ( $\mathrm{pH} 1$ ) having a similar degree of reduction where, as we extensively discussed above, $\left\{\mathrm{Mo}_{102}\right\}$-type Keplerates are generated within minutes. These results suggest that in contrast to giant wheel species, molybdenum blue Keplerates such as $\mathbf{3}$ form over a narrower $\mathrm{pH}$ range. We note here that a small modification of the synthesis procedure for $\mathbf{3 a}$, by carrying out the reaction at a slightly higher $\mathrm{pH}$ of $1.3-1.4$, results in the formation of pyramidal crystals which were crystallographically shown to contain a polyanion identical to $3{ }^{29} \mathrm{We}$ were unable to isolate crystalline samples containing 3 from solutions having a $\mathrm{pH}$ higher than 1.6.

\section{The role of the $\left\{\mathrm{Mo}_{368}\right\}$ cluster}

Thus far no attempts have been made to rationalize the formation of the "blue lemon" cluster $\left\{\mathrm{Mo}_{368}\right\}$ as a function of $\mathrm{pH}$. The $\left\{\mathrm{Mo}_{368}\right\}$ polyanion 1 has a considerably higher percentage of (formal) $\mathrm{Mo}(\mathrm{v})$ centers than the $\left\{\mathrm{Mo}_{154}\right\}$ and $\left\{\mathrm{Mo}_{176}\right\}$ wheeltype species (30.4\% vs. $18.2 \%$ respectively) although all these species are isolated from reaction mixtures with reduction degrees of about $15-20 \%$. There are two literature methods for the preparation of the $\left\{\mathrm{Mo}_{368}\right\}$ cluster: a low-yield method that 


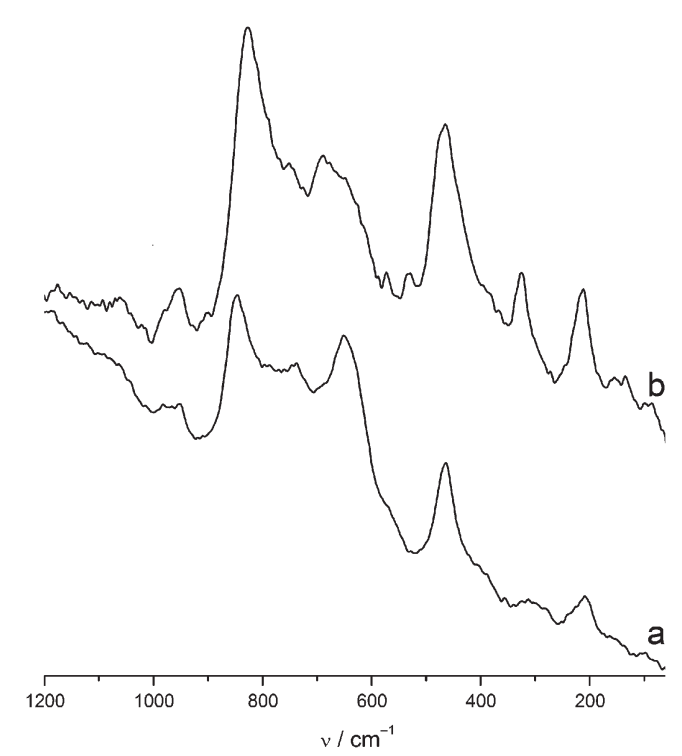

Fig. 6 Raman spectra tracking the self-assembly of the $\left\{\mathrm{Mo}_{368}\right\}$ cluster according to the literature procedure employing hydrazine sulfate as a reducing agent: (a) mother liquor of the $\left\{\mathrm{Mo}_{368}\right\}$ cluster 5 min after addition of reducing agent; (b) same solution as in (a) 30 min after addition of reducing agent and just before precipitation with $\mathrm{NaCl}$.

employs sodium dithionite as a reducing agent from which single-crystals suitable for X-ray diffraction structure determination were grown over a period of weeks ${ }^{10}$ and one that employs hydrazine sulfate from which samples were obtained after a few days. ${ }^{11}$ With the help of Raman spectroscopy we monitored the formation of the $\left\{\mathrm{Mo}_{368}\right\}$ cluster according to the sodium dithionite-based method. Within minutes after the addition of sodium dithionite to the acidified (with $\mathrm{H}_{2} \mathrm{SO}_{4}$ ) molybdate solution the highly characteristic peaks associated with wheel-type species appear. This pattern remained unchanged over a period of at least three weeks. The literature report indicates that crystals in low yield (about 3\% based on molybdenum) were obtained after two weeks. ${ }^{10}$ All these findings collectively indicate that under the given synthetic conditions the $\left\{\mathrm{Mo}_{368}\right\}$ species is only present as a minor side product. The literature method that employs hydrazine sulfate produces microcrystalline samples following addition of $\mathrm{NaCl}$ (23\% isolated yield after 2 days). ${ }^{11}$ The solution $\mathrm{pH}$ was $c a .1 .1$. The Raman spectrum of this mixture taken just before precipitation with $\mathrm{NaCl}$ is rather complex and shows a band at $c a$. $450 \mathrm{~cm}^{-1}$ also observed in solutions containing the Keplerate 3 (albeit less broad) and spectral features associated with wheel derivatives (Fig. 6). In addition, the spectrum displays another broad peak at $c a$. $650-700 \mathrm{~cm}^{-1}$ dominant at early reaction stages (i.e., immediately after the addition of hydrazine sulfate) (see Fig. 6a).

The multitude of features in the Raman spectrum suggests possible difficulties in finding the optimal conditions for the preparation of the $\left\{\mathrm{Mo}_{368}\right\}$ cluster 1. Following the literature procedure (using hydrazine sulfate) we were able to isolate microcrystalline samples of the $\left\{\mathrm{Mo}_{368}\right\}$ salt 1a within hours after addition of $\mathrm{NaCl}$. We also found that if the solution was left standing for longer than $24 \mathrm{~h}$, small dark-blue plate-like crystals began to form. These crystals were identified by IR spectroscopy to be a $\left\{\mathrm{Mo}_{102}\right\}$-type Keplerate compound (IR spectrum nearly identical to that of $\mathbf{3 a}$ ). The observation that Keplerates such as $\mathbf{3}$ form as a side product along the $\left\{\mathrm{Mo}_{368}\right\}$ cluster raises the questions whether the two cluster types could co-exist in more strongly reduced solutions from which the Keplerate $\mathbf{3}$ was shown to be optimally synthesized. The following lines of evidence rule out such a scenario: Increasing the amount of added hydrazine sulfate, compared to the literature method for the $\left\{\mathrm{Mo}_{368}\right\}$ cluster, leads to a shift in the Raman spectral pattern from that shown in Fig. $6 \mathrm{~b}$ to the one shown in Fig. 2d. Addition of $\mathrm{KCl}$ to these stronger reduced solutions exclusively produces the Keplerate compound 3a. Thus there seems to be divergent formation tendencies for the two clusters $\mathbf{1}$ and $\mathbf{3}$ with respect to $r$. Attempts to further demonstrate this trend have enabled us to find a new synthetic route for $\mathbf{1}$, namely that the use of even weakly reduced (with hydrazine sulfate) solutions $(6-10 \% v s$. $22 \%$ in the literature method) produces exclusively microcrystalline material of $\mathbf{1 a}$ and no $\left\{\mathrm{Mo}_{102}\right\}$-type side products (see Experimental section for details). In contrast to the Keplerate 3, which can be isolated both as a $\mathrm{Na}^{+}$and $\mathrm{K}^{+}$salt, the formation of $\mathbf{1}$ is clearly counterion specific. Addition of even small amounts of $\mathrm{KCl}$ to the mother liquor of $\left\{\mathrm{Mo}_{368}\right\}$ produces solutions showing only the characteristic wheel Raman spectral pattern and subsequent precipitation of these species. Thus, the conditions used for the preparation of the Keplerate 3 (addition of $\mathrm{KCl}$ to strongly reduced solutions) cannot lead to $\mathbf{1}$. All these findings collectively indicate that, in contrast to spheres and wheels, the $\left\{\mathrm{Mo}_{368}\right\}$ cluster is obtained under very narrow and specific reaction conditions. This behavior can be attributed in part to the unusual symmetry-breaking phenomenon observed at the surface of the lemon-shaped shell. A scheme summarizing the formation of the three distinct molybdenum blue structural types is given in Fig. 5 .

Establishing the formation boundaries of $\mathbf{1}$ and $\mathbf{3}$ was particularly important given the electronic similarities between the two clusters. For example, the (resonance) Raman spectrum of 1a dissolved in water is very similar (but not identical) to the corresponding spectrum of the dissolved Keplerate salt 3a (Fig. 7). These spectroscopic similarities suggests a common delocalization pattern of the $\mathrm{Mo}(4 \mathrm{~d})$ electrons in both the $\left\{\mathrm{Mo}_{102}\right\}$ and $\left\{\mathrm{Mo}_{368}\right\}$ clusters. This likely stems from the fact that both derivatives contain similar sets of building units: mixed-valent $\left\{(\mathrm{Mo}) \mathrm{Mo}_{5}\right.$ \} pentagonal building blocks as well as [MoO$\left.\left(\mathrm{H}_{2} \mathrm{O}\right)\right]^{3+}$ linker units having more localized $\mathrm{Mo}(4 \mathrm{~d})$ electrons. In spite of these similarities, the respective spectra of the two compounds allow the identification of the two species. The Raman spectrum of the solution of $\mathbf{3 a}$ exhibits a rather sharp band at $475 \mathrm{~cm}^{-1}$, a feature that is not present in the Raman spectrum of the $\left\{\mathrm{Mo}_{368}\right\}$ cluster (compare Fig. 7a and $7 \mathrm{~b}$ ). Moreover, this particular peak appears to be specific to reduced Keplerate structures since it is also present in the Raman spectrum of the mixed-valence $I_{\mathrm{h}}$-symmetric $\left\{\mathrm{Mo}^{\mathrm{V} / \mathrm{VI}}{ }_{72} \mathrm{Fe}_{30}\right\}$ Keplerate. ${ }^{30}$ In addition, the broad feature at $c a .770 \mathrm{~cm}^{-1}$ in the Raman spectrum of $\mathbf{3}$ is also present in the spectrum of $\mathbf{1}$, but is shifted by about $25 \mathrm{~cm}^{-1}$ to higher wavenumbers. In keeping with the similarities in electronic structure of the two clusters, the Vis/NIR spectrum of 1a in water shows very broad absorption features in the $600-900 \mathrm{~nm}$ region also observed in the spectrum of 3a but with a broad maximum red-shifted by about $20 \mathrm{~nm}\left(\lambda_{\max } c a .780 \mathrm{~nm}\right)$ (see Fig. 3). 


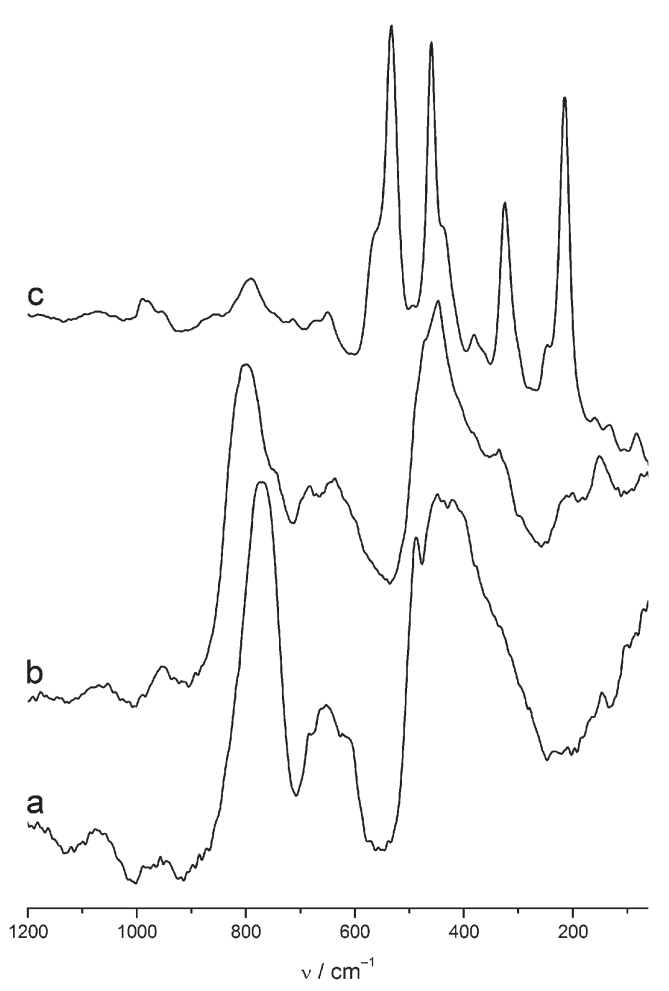

Fig. 7 Raman spectra in water of representative compounds of the three major molybdenum blue structural types: (a) the Keplerate $\left\{\mathrm{Mo}_{102}\right\} \mathbf{3 a}$; (b) the $\mathrm{Na}^{+}$salt of the lemon-shaped cluster $\left\{\mathrm{Mo}_{368}\right\} \mathbf{1 a}$; (c) the $\mathrm{Na}^{+}$salt of the $\left\{\mathrm{Mo}_{154}\right\}$ wheel-type polyanion, $2 \mathbf{a}$.

\section{Conclusions}

The combination of Raman spectroscopy and X-ray crystallography enables us to establish spherical $\left\{\mathrm{Mo}_{102}\right\}$-type Keplerates as a distinct component of molybdenum blue solutions, alongside the lemon-shaped cluster anion $\left\{\mathrm{Mo}_{368}\right\}$ and wheel-shaped clusters of the type $\left\{\mathrm{Mo}_{154}\right\}$ and $\left\{\mathrm{Mo}_{176}\right\}$. Significantly, we have demonstrated here that the controlled and selective self-assembly of these three major species that collectively constitute "giant molybdenum blue" is largely directed by the reducing agent concentration and also the solution $\mathrm{pH}$. The formation of self-organized polyoxometalate species at boundary conditions is known to result in novel structures with increased structural and hierarchical complexity. ${ }^{8}$ Thus, we will focus our future work on self-assembly processes at the boundaries in the molybdenum blue regime, aiming at the hierarchical organization of functional, and potentially supramolecular, polyoxomolybdate architectures that exploit the unique electronic and optical properties of molybdenum blues. ${ }^{4,12}$

\section{Experimental}

\section{General methods and materials}

The $\mathrm{Na}^{+}$salts of $\left\{\mathrm{Mo}_{368}\right\}$ (1a) and $\left\{\mathrm{Mo}_{154}\right\}$ (2a) were prepared according to the literature and their purity was checked by spectroscopic methods (IR, Vis/NIR and Raman). ${ }^{11,16}$ All other reagents were used as purchased without further purification.

Elemental analyses (ICP-OES, IR absorption spectroscopy for $\mathrm{S}$ ) were performed by Zentralabteilung für Chemische
Analysen (Forschungszentrum Jülich). Electronic absorption spectra were acquired on an Analytik Jena SPECORD S600 spectrophotometer equipped with a diode-array detector. Vibrational spectra were recorded on a Bruker VERTEX 70 FT-IR spectrometer coupled with a RAM II FT-Raman module. The FT-Raman module is equipped with a $1000 \mathrm{~mW} \mathrm{Nd:YAG}$ laser $(1064 \mathrm{~nm})$. Direct potentiometric titrations with cerium(IV) sulfate were performed using a Metrohm 702 SM Titrino autotitrator using freshly prepared samples. Thermogravimetric analysis (TGA) and differential thermal analysis (DTA) data were collected on a Mettler-Toledo TGA/SDTA851 instrument.

\section{Synthesis of $\mathrm{K}_{8} \mathrm{Na}_{2}(\mathrm{VO})\left[\left\{\mathrm{Mo}_{6} \mathrm{O}_{21}\left(\mathrm{H}_{2} \mathrm{O}\right)_{3}\left(\mathrm{SO}_{4}\right)\right\}_{12-}\right.$ $\left(\mathrm{MoO}\left(\mathrm{H}_{2} \mathrm{O}\right)\right)_{30} \mathrm{l} \cdot 2 \mathrm{~K}_{2} \mathrm{SO}_{4} \cdot c a \cdot 150 \mathrm{H}_{2} \mathrm{O}(3 \mathrm{a})$}

A solution of $\mathrm{NaVO}_{3}(2.6 \mathrm{~g}, 21.3 \mathrm{mmol})$ dissolved in $50 \mathrm{~mL}$ $\mathrm{H}_{2} \mathrm{O}$ at $80{ }^{\circ} \mathrm{C}$ and then cooled at room temperature was added to a solution of $\mathrm{Na}_{2} \mathrm{MoO}_{4} \cdot 2 \mathrm{H}_{2} \mathrm{O}(6.0 \mathrm{~g}, 24.8 \mathrm{mmol})$ dissolved in $60 \mathrm{~mL} \mathrm{H}_{2} \mathrm{O}$ at room temperature $(\mathrm{pH} \mathrm{7.6).} \mathrm{The} \mathrm{mixture} \mathrm{was}$ acidified to $\mathrm{pH} 1.0$ with $\mathrm{H}_{2} \mathrm{SO}_{4}(2 \mathrm{M} ; 45 \mathrm{~mL})$ and then the resulting yellow solution was treated with $\mathrm{N}_{2} \mathrm{H}_{6} \mathrm{SO}_{4}$ (1.5 g, $11.5 \mathrm{mmol})$. Upon addition of reducing agent, the solution instantly turned green with effervescence and then within a minute dark-blue-violet. The mixture was stirred at room temperature for $2 \mathrm{~h}$ and then treated with solid $\mathrm{KCl}(3.0 \mathrm{~g}$, $40.2 \mathrm{mmol}$ ) added in small portions. Blue-black square crystals started to form after 10-20 min. Yield after 3 days: 1.0 g. (20\% based on Mo). Following a nearly identical synthetic procedure but carried out at a higher $\mathrm{pH}$ (1.4), pyramidal crystals of the same compound were obtained after several days. Elemental composition, calculated for $\mathrm{H}_{432} \mathrm{O}_{555} \mathrm{~K}_{12} \mathrm{Na}_{2} \mathrm{~S}_{14} \mathrm{~V}_{1} \mathrm{Mo}_{102}$ $\left(M=20116.3 \mathrm{~g} \mathrm{~mol}^{-1}\right)$ : K, 2.33; Na, 0.23; S, 2.23; Mo 48.65; V, 0.25. Found: K, 2.47; Na, 0.29; S, 2.20; Mo, 46.5; V, 0.4\% (average values from three independently synthesized samples). The number of crystal water molecules was determined by thermogravimetric analysis (Fig. S3†); ca. 23.7\% mass loss between 30 and $550{ }^{\circ} \mathrm{C}$ corresponding to the loss of $c a .215$ water molecules (water molecules of crystallization and coordinated aqua ligands) and decomposition of 14 sulfates (lost as $\left.\mathrm{SO}_{2}\right)$. Direct cerimetric potentiometric titrations $\left( \pm 1 \mathrm{e}^{-}\right)$: 36.5 Mo(v) centers. IR ( $\mathrm{KBr}$ pellet; 2000-400 $\left.\mathrm{cm}^{-1}\right)$ : 1608 $\left(\mathrm{m}-\mathrm{s}, \delta\left(\mathrm{H}_{2} \mathrm{O}\right)\right), 1180 \mathrm{sh}(\mathrm{w}), 1110 \mathrm{sh}(\mathrm{w})$ (both $\left.v_{\text {as }}\left(\mathrm{SO}_{4}\right)\right), 978$ (m-s), 954 (s) (both $v\left(\mathrm{Mo}-\mathrm{O}_{\text {term }}\right)$ ), 755 (m-s), $680(\mathrm{~m}), 632(\mathrm{~m})$, $554(\mathrm{~m}), 452$ (m) (Fig. S2 $\uparrow$ ). Resonance-Raman (in $\mathrm{H}_{2} \mathrm{O}, \lambda_{\mathrm{e}}=$ 1064 nm): 770 (s), 653 (m-w), 487 (s), 450 (s, br), 147 (w). Electronic absorption spectra $\left(350-1020 \mathrm{~nm}\right.$, in $\mathrm{H}_{2} \mathrm{O}$ at natural $\mathrm{pH} 3.8 ; c=0.08 \mathrm{mM})\left[\lambda_{\max } / \mathrm{nm}\left(\varepsilon / \mathrm{M}^{-1} \mathrm{~cm}^{-1}\right)\right]: c a .760 \mathrm{br}$ $\left(\right.$ IVCT $\mathrm{Mo}^{\mathrm{VI}} \leftarrow \mathrm{Mo}^{\mathrm{V}} ; 1.4 \times 10^{5}$ ).

\section{Optimized synthesis of $\mathrm{Na}_{48-x}\left[\mathrm{H}_{x} \mathrm{Mo}_{368} \mathrm{O}_{1032}\left(\mathrm{H}_{2} \mathrm{O}\right)_{240}\left(\mathrm{SO}_{4}\right)_{48}\right]^{\cdot}$ ca. $1000 \mathrm{H}_{2} \mathrm{O}$ (1a)}

A solution of $\mathrm{Na}_{2} \mathrm{MoO}_{4} \cdot 2 \mathrm{H}_{2} \mathrm{O}(6.0 \mathrm{~g}, 24.8 \mathrm{mmol})$ dissolved in $160 \mathrm{~mL} \mathrm{H}_{2} \mathrm{O}$ was acidified at room temperature to $\mathrm{pH} 1.0$ with $\mathrm{H}_{2} \mathrm{SO}_{4}(2 \mathrm{M} ; 33 \mathrm{~mL})$. Following addition of $\mathrm{N}_{2} \mathrm{H}_{6} \mathrm{SO}_{4}(0.05 \mathrm{~g}$, $0.38 \mathrm{mmol}$ ) the solution turned violet within a few minutes. After $30 \mathrm{~min}$ of stirring at room temperature the resulting dark-blue-violet solution was transferred to a wide-necked 
Table 1 Crystal data and structure refinement details for $\mathbf{3 a}$

\begin{tabular}{|c|c|}
\hline Formula & $\mathrm{H}_{432} \mathrm{O}_{555} \mathrm{~K}_{12} \mathrm{Na}_{2} \mathrm{~S}_{14} \mathrm{~V}_{1} \mathrm{Mo}_{102}$ \\
\hline Crystal color, habit & Blue-black, square \\
\hline Crystal size $/ \mathrm{mm}^{3}$ & $0.31 \times 0.17 \times 0.06$ \\
\hline Crystal system & Monoclinic \\
\hline Space group & $C 2 / c$ \\
\hline \multicolumn{2}{|l|}{ Unit cell } \\
\hline$a / \AA$ & $44.4160(6)$ \\
\hline$b / \AA$ & $26.5633(3)$ \\
\hline$c / \AA$ & $44.7030(5)$ \\
\hline$\beta$ & $103.820(1)^{\circ}$ \\
\hline$V / \AA^{3}$ & $51215(1)$ \\
\hline$Z$ & 4 \\
\hline $\mathrm{Fw} / \mathrm{g} \mathrm{mol}^{-1}$ & 20116.3 \\
\hline$\rho_{\text {calc }} / \mathrm{g} \mathrm{cm}^{-3}$ & 2.61 \\
\hline$\mu, \mathrm{mm}^{-1}$ & 2.71 \\
\hline$F(000)$ & 38612 \\
\hline$\theta$ range & $2.89^{\circ}$ to $23.82^{\circ}$ \\
\hline Total no. of data & 317408 \\
\hline Indep. reflns. & $39248\left(R_{\mathrm{int}}=0.0524\right)$ \\
\hline No. of obsd. data $(I>2 \sigma(I))$ & 32134 \\
\hline No. of restraints & 678 \\
\hline No. of params. & 3231 \\
\hline$R_{1}^{a}(I>2 \sigma(I))$ & 0.0850 \\
\hline$w R_{2}^{b}(I>2 \sigma(I))$ & 0.2082 \\
\hline GOF on $|F|^{2}$ & 1.10 \\
\hline Largest diff peak and hole, e $\mathrm{A}^{-3}$ & $4.51 ;-2.54$ \\
\hline \multicolumn{2}{|c|}{${ }^{a} R_{1}=\Sigma|| F_{\mathrm{o}}|-| F_{\mathrm{c}}|| /\left|F_{\mathrm{o}}\right| \cdot{ }^{b} \mathrm{w} R_{2}=\left\{\sum\left[\mathrm{w}\left(F_{\mathrm{o}}{ }^{2}-F_{\mathrm{c}}{ }^{2}\right)^{2}\right] / \sum\left[\mathrm{w}\left(F_{\mathrm{o}}{ }^{2}\right)^{2}\right]\right\}^{0.5}}$. \\
\hline
\end{tabular}

Erlenmeyer flask and left to crystallize in the open flask. The solution $\mathrm{pH}$ remained constant at 1.0. Blue-black crystals of 1a formed after 3-5 days. Yield: ca. $0.9 \mathrm{~g}$ (17\% based on Mo). IR ( $\mathrm{KBr}$ pellet; 2000-400 $\left.\mathrm{cm}^{-1}\right)$ : $1608\left(\mathrm{~s}, \delta\left(\mathrm{H}_{2} \mathrm{O}\right)\right), 1195(\mathrm{w})$, 1105 (w), 1065 (w) (all $\left.v_{\text {as }}\left(\mathrm{SO}_{4}\right)\right), 981$ (ms), 959 (s) (both $\left.v\left(\mathrm{Mo}-\mathrm{O}_{\text {term }}\right)\right), 766(\mathrm{vs}), 690 \mathrm{sh}, 631(\mathrm{~m}), 588(\mathrm{~s}), 465(\mathrm{w})$ (Fig. S2 $\dagger$ ). Electronic absorption spectra $\left(350-1020 \mathrm{~nm}\right.$, in $\mathrm{H}_{2} \mathrm{O}$ at natural pH 3.0; $c=0.029 \mathrm{mM})\left[\lambda_{\max } / \mathrm{nm}\left(\varepsilon / \mathrm{M}^{-1} \mathrm{~cm}^{-1}\right)\right]$ : $c a$. $780 \mathrm{br}\left(\mathrm{IVCT} \mathrm{Mo}{ }^{\mathrm{VI}} \leftarrow \mathrm{Mo}^{\mathrm{V}} ; 2.4 \times 10^{5}\right)$.

\section{X-Ray crystallography}

Crystals of 3a were taken directly from the mother liquor, mounted on a cryoloop sample holder and immediately cooled to 173(2) K on an Oxford SuperNova diffractometer equipped with monochromated Mo-K $\alpha(0.71073 \AA)$ radiation. $\dagger$ A numerical absorption correction based on Gaussian integration over a multifaceted crystal model was performed with the program CrysAlisPro (Oxford Diffraction). The structure was refined in full-matrix anisotropic approximation. Structure solution, refinement and generation of publication materials were performed using SHELXTL. ${ }^{31}$ For additional crystallographic parameters see Table 1. The structure refinement of $\mathbf{3 a}$ posed a series of challenges stemming from the complexity and size of the molecule and especially from the disorder of the encapsulated sulfate groups. This disorder, independent of the crystal quality, stems solely from the high symmetry of the spherical cluster anion. All encapsulated sulfur atoms were found to be disordered over five sites (five possible attachment modes of the sulfate ions to the pentagonal units) with a total occupancy of 1 . Their terminal oxo ligands are also underoccupied and, as a result, difficult to locate due to their very low electron density. Strong similarity constraints and restraints were applied to atoms of the 12 inner sulfate groups to force the relevant geometry of the moiety and atom ADPs. This is a standard procedure for refinement of giant polymolybdate clusters. One vanadyl cation found by elemental analysis could not be crystallographically identified, and is most likely disordered in the large voids between the spherical cluster ions. Some water molecules of crystallization, $\mathrm{K}^{+}$and $\mathrm{Na}^{+}$counterions as well as the two non-coordinated sulfate groups could not be located due to disorder. Similar situations have been observed in other Keplerate structures. ${ }^{20-22}$

\section{References}

1 Special issue on "Supramolecular Chemistry and Self-assembly", Proc. Natl. Acad. Sci. U. S. A., 2002, 99, 4762.

2 (a) G. M. Whitesides, J. P. Mathias and C. T. Seto, Science, 1991, 254, 1312; (b) M. Boncheva and G. M. Whitesides, MRS Bull., 2005, 30, 736.

3 (a) Y. Liu, C. Hu, A. Comotti and M. D. Ward, Science, 2011, 333, 436; (b) Q.-F. Sun, J. Iwasa, D. Ogawa, Y. Ishido, S. Sato, T. Ozeki, Y. Sei, K. Yamaguchi and M. Fujita, Science, 2010, 328, 1144.

4 To avoid the ambiguity and confusion that has been historically associated with the term "molybdenum blue" we strictly refer to discrete, molecular "soluble molybdenum blue" species as opposed to colloidal or polymeric mixed-valent molybdenum oxide species, see also: A. Müller and C. Serain, Acc. Chem. Res., 2000, 33, 2. We also distinguish between giant molybdenum blue clusters and the molecular species termed "heteropoly blues", referring to reduced isopoly- and heteropolyanions regardless of their color. These species include the following types of structures (and their derivatives): Keggin $\left(\left\{\mathrm{XM}_{12} \mathrm{O}_{40}\right\}\right)$, Dawson $\left(\left\{\mathrm{X}_{2} \mathrm{M}_{18} \mathrm{O}_{62}\right\}\right)$, Lindqvist $\left(\left\{\mathrm{M}_{6} \mathrm{O}_{19}\right\}\right)$ and decatungstate $\left(\left\{\mathrm{W}_{10} \mathrm{O}_{32}\right\}\right)$. For details see: (a) M. T. Pope, Heteropoly and Isopolyoxometalates, Springer Verlag, Berlin, Germany, 1983; (b) M. T. Pope, Polyoxo anions: synthesis and structure, in Comprehensive Coordination Chemistry II: Transition Metal Groups 3-6, ed. A. G. Wedd, Elsevier Science, New York, NY, USA, 2004, vol. 4, ch. 4.10, pp. 635-678.

5 A. Müller, E. Krickemeyer, J. Meyer, H. Bögge, F. Peters, W. Plass, E. Diemann, S. Dillinger, F. Nonnenbruch, M. Randerath and C. Menke, Angew. Chem., Int. Ed. Engl., 1995, 34, 2122.

6 A. Müller, J. Meyer, E. Krickemeyer and E. Diemann, Angew. Chem., Int. Ed. Engl., 1996, 35, 1206.

7 A. Müller, E. Krickemeyer, H. Bögge, M. Schmidtmann, C. Beugholt, P. Kögerler and C. Lu, Angew. Chem., Int. Ed., 1998, 37, 1220.

8 B. Botar, P. Kögerler and C. L. Hill, J. Am. Chem. Soc., 2006, 128, 5336.

9 In mixed-valent wheel-type polyoxomolybdates the molar extinction coefficients of the IVCT absorption bands are approximately linear in the number of Mo(4d) electrons, see: ref. 4

10 A. Müller, E. Beckmann, H. Bögge, M. Schmidtmann and A. Dress, Angew. Chem., Int. Ed., 2002, 41, 1162.

11 A. Müller, B. Botar, S. K. Das, H. Bögge, M. Schmidtmann and A. Merca, Polyhedron, 2004, 23, 2381.

12 A. Müller and S. Roy, Coord. Chem. Rev., 2003, 245, 153.

13 A. Müller, P. Kögerler and H. Bögge, Struct. Bonding, 2000, 96, 203.

14 L. Cronin, P. Kögerler and A. Müller, J. Solid State Chem., 2000, 152, 57.

15 H. N. Miras, G. J. T. Cooper, D.-L. Long, H. Bögge, A. Müller, C. Streb and L. Cronin, Science, 2009, 327, 72.

16 A. Müller, S. K. Das, E. Krickemeyer and C. Kuhlmann, Inorg. Synth., 2004, 34, 191.

17 Compound 2a was shown to contain two crystallographically independent polyanions: the intact $\left\{\mathrm{Mo}_{154}\right\}$ wheel and its vacant $\left\{\mathrm{Mo}_{152}\right\}$ derivative (which lacks a $\left\{\mathrm{Mo}_{2}\right\}$ group) (see ref. 18 for details)

18 A. Müller, S. K. Das, V. P. Fedin, E. Krickemeyer, C. Beugholt, H. Bögge, M. Schmidtmann and B. Hauptfleisch, Z. Anorg. Allg. Chem., 1999, 625, 1187.

19 Vanadate ions have been previously used for the purpose of growing diffraction quality crystals of wheel-type derivatives (see ref. 5)

20 A. Müller, B. Botar, H. Bögge, P. Kögerler and A. Berkle, Chem. Commun., 2002, 2944

21 B. Botar, P. Kögerler, A. Müller, R. Garcia-Serres and C. L. Hill, Chem. Commun., 2005, 5621 
22 B. Botar, A. Ellern, M. T. Sougrati and P. Kögerler, Eur. J. Inorg. Chem., 2009, 5071.

23 A. Müller, S. Q. N. Shah, H. Bögge, M. Schmidtmann, P. Kögerler, B. Hauptfleisch, G. Leiding and K. Wittler, Angew. Chem., Int. Ed., 2000, 39, 1614.

24 A. Müller, E. Krickemeyer, H. Bögge, M. Schmidtmann and F. Peters, Angew. Chem., Int. Ed., 1998, 37, 3360.

25 A. Müller, S. Polarz, S. K. Das, E. Krickemeyer, H. Bögge, M. Schmidtmann and B. Hauptfleisch, Angew. Chem., Int. Ed., 1999, 38, 3241.

26 A. Müller, C. Beugholt, M. Koop, S. K. Das, M. Schmidtmann and H. Bögge, Z. Anorg. Allg. Chem., 1999, 625, 1960.

27 S. Shishido and T. Ozeki, J. Am. Chem. Soc., 2008, 130, 10588.

28 Prolonged ageing of the molybdenum blue solutions used in these studies shows no appreciable oxidative degradation (by air oxygen) of these mixed-valent $\mathrm{Mo}(\mathrm{v}) / \mathrm{Mo}(\mathrm{vI})$ species. For instance mixtures from which the $\left\{\mathrm{Mo}_{102}\right\}$-type Keplerate compound 3a was obtained aged for 3 to 4 weeks, exhibit Raman spectra virtually identical to that of a 2 hour-old mixture, with no noticeable decrease in band intensity

29 The compound crystallizes as a $\mathrm{K}^{+}$salt in the tetragonal space group $\mathrm{P4}_{2}$ $n c m, a=39.1211(1), b=33.1098(2) \AA, V=50673(1) \AA^{3}, Z=4$. This compound and 3a both contain the same $\left\{\mathrm{Mo}_{102}\right\}$ Keplerate and both compounds appear to have a similar degree of reduction based on electronic absorption spectroscopy (nearly identical extinction coefficients)

30 B. Botar, A. Ellern, R. Hermann and P. Kögerler, Angew. Chem., Int. Ed., 2009, 48, 9080.

31 G. M. Sheldrick, Acta Crystallogr., Sect. A: Found. Crystallogr., 2007, 64, 112.

32 A. Müller, P. Kögerler and C. Kuhlmann, Chem. Commun., 1999, 1347. 